\title{
Interface entre pensamento obsessivo e delírio: relato de dois casos
}

\author{
Interfacing delusion and obsessive thought: two case reports
}

\begin{abstract}
Andres Santos Jr. ${ }^{1}$, Débora Pastore Bassitt ${ }^{2}$
${ }^{1}$ Psiquiatra. Encarregado do Ambulatório de Psiquiatria e Preceptor da Residência em Psiquiatria, Hospital do Servidor Público Estadual de São Paulo (HSPE/SP), São Paulo, SP. Responsável pelo Curso de Psicopatologia, HSPE/SP. ${ }^{2}$ Psiquiatra. Doutora. Preceptora do Ambulatório de Psiquiatria e Professora do Curso de Pós-Graduação, HSPE/SP. Coordenadora, Enfermaria, Projeto Terceira Idade (PROTER), Hospital de Clínicas, Universidade de São Paulo (USP), São Paulo, SP.
\end{abstract}

\section{Resumo}

As dificuldades psicopatológicas de distinção entre pensamento delirante e pensamento obsessivo impõem reflexões. Na clínica, é comum a sobreposição de sintomas, o que promove dificuldades na distinção de categorias tão diversas. Discutem-se dois casos em que ambos os diagnósticos, pelos critérios do Manual de Diagnóstico e Estatística das Perturbações Mentais, são possíveis. Aplicamse as escalas PANSS (Positive and Negative Syndrome Scale) e Yale-Brown Obsessive-Compulsive Scale, que não esclarecem as diferenças. Na busca de uma melhor formulação diagnóstica, é proposto um diálogo com as idéias de Carol Sonenreich em contraponto com as classificações dos códigos, manuais e literatura contemporânea.

Descritores: Comportamento obsessivo, delírio, psicopatologia, diagnóstico diferencial.

\begin{abstract}
In psychopathology, the difficulties in distinguishing between delusion and obsessive thought require some reflection. There is a significant degree of uncertainty and complexity surrounding these categories, the symptoms of which seem to overlap each other. Two cases are presented in which both diagnoses are plausible using criteria of the Diagnostic and Statistical Manual of Mental Disorders. The Positive and Negative Syndrome Scale and Yale-Brown Obsessive Compulsive Scale were applied, but did not help clarify the differences. In search for the best diagnosis, a dialogue with the studies of Carol Sonenreich is herein proposed in a counterpoint to code classifications, guides and the state-of-the-art literature.
\end{abstract}

Keywords: Obsessive behavior, delirium, psychopathology, diagnosis, differential.

\section{Introdução}

Este artigo estuda os conceitos de pensamento delirante e pensamento obsessivo. O objetivo é discutir controvérsias surgidas no campo psicopatológico, exemplificando com dois casos estudados na clínica, base de nossas reflexões. Nossa escolha é o diálogo com as idéias de Carol Sonenreich. Em contraponto às categorias classificatórias dos códigos, manuais atuais e literatura contemporânea, Sonenreich concebe a diferença entre pensamento obsessivo e delírio na relação entre o médico e seu paciente baseada na comunicação lógica. A perda desta isolaria e determinaria o fracasso nas experiências pessoais dos delirantes, o que não ocorre nos quadros obsessivocompulsivos. Propomos que a melhor formulação diagnóstica visaria a um projeto terapêutico mais adequado, contribuindo, assim, à prática clínica.

\section{Método}

Dois pacientes serão estudados. Os respectivos diagnósticos foram realizados com base no Manual de 
Diagnóstico e Estatística das Perturbações Mentais (DSM-IV). Também foram aplicadas as escalas: Structured Clinical Interview for DSM (SCID), Positive and Negative Syndrome Scale (PANSS) e Yale-Brown Obsessive-Compulsive Scale (Yale-Brown). Uma revisão de psicopatologia será realizada. A discussão terá como base artigos selecionados, que tratam do diálogo entre delírio e pensamento obsessivo.

\section{Casos clínicos}

Os casos a seguir têm características semelhantes: são pacientes da clínica particular, com diagnósticos prévios, feitos por profissionais da área de saúde mental. Temos as autorizações para este estudo fornecidas pelos pacientes.

\section{Caso 1: o senhor $\mathbf{R}$.}

R. tinha 22 anos quando chegou ao consultório, encaminhado pela irmã psicóloga, que havia feito a hipótese de um quadro obsessivo-compulsivo. R. estudava agronomia, em seu último ano. Aluno razoável, de desempenho mediano, preparava-se para assumir a administração da fazenda do pai após a graduação. Gostava de freqüentar um centro espírita de orientação umbandista e era muito afeiçoado ao médium orientador desse centro. Certa noite, voltando da sessão religiosa, na véspera de seu aniversário de 22 anos, apresentou mal-estar súbito. Apoiou-se a uma árvore e teve uma visão que descreve assim:

Ficou tudo escuro e por um instante eu não vi nada, ai olhei para cima da árvore e vi Jesus Cristo crucificado no tronco desta. Estava nu e olhava para mim. Eu o via de baixo para cima e assim seu pênis balançava em minha direção. Fixando o olhar, percebi que o pênis crescia e alongava-se e curvando-se para trás penetrava o ânus até formar uma curva estranha, como uma tromba de elefante quando este se alimenta. Fiquei olhando um tempão e aí acho que desmaiei. Só acordei de madrugada quando um guarda me sacudia e me levou para a república em que eu morava, e lá meus amigos chamaram minha mãe, que veio buscar-me.

Estes fatos ocorreram cerca de 10 dias antes da primeira entrevista conosco. Do momento da visão em diante, R. percebia-se obrigado a realizar certos rituais: fugir de pessoas de branco - como os médiuns do centro -, rezar ajoelhado horas a fio, beber a própria urina para purificar-se, jejuar e não dormir em camas para penitenciar-se. Esses atos eram observados pela família sem que houvesse quaisquer explicações por parte de R.
Conta, então, que tudo começara após um abortamento ao qual a namorada submetera-se. $\mathrm{O}$ "espírito" do bebê obrigava-o a fazer certas coisas que não queria. Sofria com esse fato, mas sabia-o irreversível; assim, teria de fazer penitências pelo resto da vida.

Iniciamos medicação antipsicótica, Sulpiride, 600 $\mathrm{mg}$ ao dia, havendo melhoras do sono e do comportamento hostil desde os primeiros dias. Mais tranqüilo, é capaz de contar-nos o que lhe ocorreu:

Ia ao centro espirita e ficava ouvindo o orientador falar sobre pecados que se pagam via reencarnações. Então comecei a ouvir vozes que me revelaram o meu passado: eu era Deus, o que havia criado o Deus que todo mundo conhece. Havia feito um plano em que toda a violência e mal-estar no mundo terminariam, era só plantar mais mandioca e acabar com os metais! A mandioca alimentaria a todos, e sem metais, dinheiro e armas não mais existiriam. Os anjos e arcanjos ficaram tão felizes com suas revelações que depuseram o velho Deus e me elegeram no lugar dele!

Ele então se "lembrou" que, como Deus, deveria ser assexuado ou bissexual, ocasião em que tivera a visão de Jesus Cristo e o colapso. R. nasceu em casa de família de classe média alta, sendo criado em boas condições de informação e estudo universitário. Entre os 13 e 14 anos, iniciou atividade homossexual com um primo próximo, de quem gostava muito. Sempre no papel submisso, o que o agradava. Aos 19 anos, a namorada de 17 anos engravidou e teve a gestação interrompida contra a vontade de $\mathrm{R}$.

Descreve-se e era visto como jovem sensível e amoroso, o que explicaria seu enorme sucesso com as mulheres. O interesse religioso surgiu aos 21 anos, pouco antes do quadro agudo, iniciando orações quando soube que provavelmente o casamento de seus pais seria desfeito. Freqüentava um centro espírita quase diariamente, fazia promessas para que os pais ficassem juntos. Começou a desenvolver certos rituais que considerava seguros para atingir sua finalidade.

Juntava o "choro" de uma vela num papel limpo e, após esfriar, devia moldar uma cruz, beijá-la e lambêla, depois derretê-la de novo misturando-a com fezes e urina para purificação. Nesse estado, a cruz era jogada na privada. Tinha que fazer isso nove vezes por dia, pois "só novenas" funcionariam.

Jejuar e orar eram outras maneiras de fazer os espíritos obedecerem: comia uma folha de alface com um pouquinho de terra, assim honrava a mãe natureza; bebia urina para "limpar por dentro" e dormia no chão ao lado da cama.

Falava a todos com muita paz e serenidade, no objetivo de fazê-los compreender sua nova condição 
divina; sabia que era escolhido, pois ele mesmo se escolhera para salvar a humanidade.

Não podia masturbar-se: assim desenvolveria força de milagre. Postulava a castidade prazerosa como saída para as perversões sexuais da humanidade. Os espíritos o orientavam e diziam exatamente o que fazer, ele só tinha que obedecer.

Fizemos hipóteses e usamos escalas para esclarecer o diagnóstico. R., segundo o DSM-IV, é compatível com transtorno delirante persistente, mas também com transtorno obsessivo-compulsivo (TOC). Citamos pensamentos, impulsos ou imagens recorrentes e persistentes que, em algum momento durante a perturbação, são experimentados como intrusivos e inadequados e causam acentuada ansiedade ou sofrimento. Os pensamentos, impulsos ou imagens não são meras preocupações excessivas com problemas da vida real. A pessoa tenta ignorar ou suprimir tais pensamentos, impulsos ou imagens, ou neutralizá-los com algum outro pensamento ou ação (critérios diagnósticos para F42.8-300.3, transtorno obsessivo-compulsivo, de acordo com o DSM-IV, de 1994) ${ }^{1}$. Tais elementos explicariam a hipótese de TOC.

As aplicações das escalas PANSS ${ }^{2}$ e Yale-Brown ${ }^{3}$ revelaram, respectivamente:

PANSS (escores):

- Geral: 56

- Positivos: 35 (delírios $=6$; comportamento alucinatório $=4$ )

- Negativos: 19

Yale-Brown (19 itens): 52

A evolução do caso se deu de forma a comprovar a apresentação psicopatológica de delírio. Respondeu aos antipsicóticos e, durante a psicoterapia proposta, evidenciou-se a ruptura da comunicação lógica e impossibilidade de atuar ou funcionar em segunda alternativa. Este modo de conceber o delírio será discutido mais adiante.

\section{Caso 2: o senhor A.}

O paciente A. nos procurou no consultório em 1988, encaminhado para avaliação por colega psicanalista, que suspeitava de esquizofrenia paranóide. Tinha 28 anos, era branco, solteiro, engenheiro de informática, noivo, com boa aparência geral. As queixas eram vagas: dizia estar mal no seu noivado e pressionado para se casar. Não dormia bem, estava desconcentrado no trabalho, sempre com a impressão de que algo iria lhe acontecer. Desconfiava de todos à sua volta: pareciam rir dele às suas costas e às vezes tinha a impressão de ouvir vozes que o chamavam, confundindo-se com seus próprios pensamentos; apesar do absurdo, reconhecia que isto era produto de "sua cabeça".
Considerava-se e era reconhecido como muito bom profissional. Seu trabalho principal era buscar fora do país conhecimento e técnicas apropriadas ao incremento da indústria informática brasileira. Descrevia sua atividade sexual como satisfatória. Iniciou vida sexual aos 18 anos, em idade que achou boa. Não ficava à vontade com o assunto e evitava ser mais claro ou explícito. Nunca usou drogas. Álcool, só com muita moderação. Os pais eram vivos, com boa saúde, e ele era filho único, sem quaisquer outros antecedentes de doença na família.

Mostrava-se incapaz de fornecer qualquer explicação ao seu mal-estar e, nos primeiros encontros, apesar de disposto a colaborar, não conseguia efetivamente fazê-lo.

A descrição a seguir é uma síntese de vários encontros com o paciente. Procuramos manter a ordem cronológica de suas revelações, adaptando-as a um formato mais claro aos nossos propósitos. A gramática e as palavras foram ligeiramente alteradas.

O início do relato significativo do senhor A. se deu desta forma:

Ontem, peguei um filme no videoclube que quando passou no cinema tive muito medo de assistir. Era "O exorcista", e nesse filme o cara salva uma menina possuida; possuida, doutor! Você imagina isto? Ela chega a se masturbar com um crucifixo; um crucifixo, meu Deus do céu. Só Deus mesmo para entender como alguém fica assim. Ainda bem que o padre vai e salva a menina. O padre morre no lugar dela.

Perguntamos: "Para que está repetindo certas palavras - 'exorcista', 'possuída', 'crucifixo'? Há motivos?". Visivelmente transtornado, começa a tremer, torcendo as mãos, em movimentos expressivos do momento de grande ansiedade pelo qual passava, e finalmente diz que "precisava falar assim" para que nada de ruim lhe acontecesse: "Eu tenho um delírio, doutor".

Para explicar suas atitudes ou a razão de seu malestar, após certa resistência, fala:

Isto começou faz tempo, eu tinha uns 14 anos e estava numa intensa fase masturbatória! Certa noite, meus pais saíram e eu fiquei sozinho em casa, resolvi então me masturbar na própria cama deles, masturbar na cama deles! Havia pegado um pedaço de papel higiênico do banheiro deles, mas estava tão empolgado que o esperma escapou do papel e me melou todo, nas mãos e na barriga. Levantei, fui ao banheiro deles e lavei as mãos, enxuguei na toalha de rosto deles $e$ conferi várias vezes a cama para ver se havia sobrado algo. Fui deitar e dormi rapidamente, nem ouvindo quando eles chegaram. Acordei no meio da noite com muito medo: eu sabia [grifo do paciente] que havia 
cometido um pecado, um pecado tão grande que eu seria castigado com certeza. No dia seguinte, tudo parecia normal. Com o passar dos dias, quase esqueci o acontecido, ou pelo menos não pensava mais nisso. Algum tempo depois, fomos acordados pelo telefone no meio da noite, e eu comecei a ouvir meu pai falar alto e minha mãe chorar. Imediatamente, tudo voltou na minha cabeça. Algo tinha acontecido e devia ser por minha culpa, o pecado e o castigo, eu pensava repetidamente: o pecado e o castigo...

A notícia vinha da esposa de um tio que o encontrara morto, enforcado por suicídio, e pedia ajuda ao meu pai. Fomos todos ao velório. Os filhos dele eram um pouco maiores do que eu, e apesar de tentar falar com eles ou brincar um pouco não deu certo, parecia que me olhavam de um jeito diferente e eu comecei a achar que eles sabiam. Apesar de saber que era um absurdo, eu comecei a ter certeza que Deus, sim, Deus só podia estar me castigando. Eu era responsável pela morte daquele cara que eu gostava tanto e não tinha me feito nada de ruim, nunca! A primeira reação a essa culpa foi uma decisão: nunca mais iria me masturbar, eliminando, assim, qualquer perigo futuro! Parei mesmo completamente de me masturbar. Dormia mal, deixei de me concentrar na escola, e a minha performance, até aquele momento muito boa, começou a deixar a desejar. Abandonei as aulas de violão e de inglês e comecei a ir muito à igreja. Tinha ereções dolorosas quase todas as noites e evitava dormir de bruços, minha posição favorita, para diminuir a excitação que sentia.

A solução encontrada pelo paciente é descrita brevemente, pois constava de várias páginas, com longas e complicadas equações:

Eu rezava tanto que um dia tive uma iluminação: o terço é uma parte do rosário.

Neste, há 5 mistérios, ou seja, repete-se 5 vezes: 1 Pai-Nosso, 10 Ave-Marias e 1 Glória, igual a $5+50+5$.

O rosário é 3 vezes o terço, portanto: $15+150+15$.

Os dois totais somados: $60+180=240$.

Ainda somando os algarismos, $6+0=6$ e $1+8+$ $0=9$, assim como o rosário reza-se para enormes pecados, pelo imenso tempo que demanda, ele (o rosário) aproxima mais o homem de Deus, e Deus gosta mais de quem reza mais, e o terço é coisa para preguiçosos, pois leva muito menos tempo.

Sendo a preguiça um dos pecados capitais, que são 7, o demônio gosta mais do terço, e o demônio sabe que é pouco só um terço para grandes pecados.

$O$ número do terço é 6 , que também é o número da besta (a besta como está na Bíblia).

O número do rosário é 9, ou seja, noves fora zero, que é o número que representa Deus, porque é absoluto como Deus.
Como os homens são fracos e pecam muito, somando $6+9=15$, que, somando os algarismos, é 5 $+1=6$ : de novo o número do demônio.

Concluindo: o 6 é igual ao 1 (o demo), o 9 é igual a zero (Deus).

Assim: 6 (demônio) +1 (homem) $=7=$ número dos pecados.

Já: 9 (Deus) +1 (homem) $=10=$ dezena, par, múltiplo de 2 e com o zero de Deus.

Final: tudo que é par é de Deus, a maior marca do par é o zero, pois é absoluto, não precisa dos homens, assim, zero ou par é de Deus, e l ou ímpar é do demônio, ser imperfeito que precisa do homem para pecar. Toda unidade é do demônio!

A partir dessa descoberta, começou uma nova fase na vida do senhor A. Ele nos conta:

Quando resolvi a equação divina, tudo se modificou para mim. Num dia de ausência de meus pais, fui ao quarto deles e novamente masturbei-me em sua cama! Assim, resolvi o problema do meu prazer solitário: era só me masturbar duas vezes. Fiquei muito amigo de tudo que é par e inimigo do ímpar, mas, com o passar do tempo, essa libertação inicial virou minha condenação. Tinha e tenho medo de tudo que não é duplo ou passivel de anulação.

Além da psicoterapia, optamos por tratar com medicamentos sintomáticos suas manifestações ansiosas e a repetição, aritmomaníaca, a que estava submetido. Medicado com Amitriptilina em doses crescentes, de $25 \mathrm{mg}$ a $75 \mathrm{mg}$ por dia, em duas semanas recuperou o sono, e diminuíram perceptivelmente as manifestações somáticas da ansiedade. A psicoterapia também foi essencial para o tratamento.

As nossas dificuldades diagnósticas impuseram-se desde o início: o componente obsessivo-compulsivo, os elementos fóbicos evidentes, além das idéias delirantes já diagnosticadas previamente ao nosso contato com o paciente. Quando pensamos em critérios para o pensamento delirante proposto por Jaspers, senhor A. preenche a todos (certeza subjetiva notável, impermeável à argumentação lógica, conteúdo do relato inverossímil).

Claro que, apesar do possível quadro delirante, não cremos que alguém o colocasse no capítulo esquizofrenia. Pelos critérios do DSM-IV, seu quadro pode ser compatível tanto com TOC quanto com transtorno delirante persistente.

A aplicação das escalas PANSS e Yale-Brown mostrou o seguinte resultado:

PANSS (escores):

- Geral: 55

- Positivos: 32

- Negativos: 17 
Yale-Brown (19 itens): 52

Caberia aqui uma observação (não quanto à inacurácia das escalas, cuja finalidade, na pesquisa, está muito bem delineada): ambos os pacientes apresentaram escores muito próximos, tanto na PANSS quanto na Yale-Brown. Reconhecemos, com Araújo ${ }^{4}$, que ambas não têm finalidade diagnóstica. Não discriminam de forma confiável diferenças entre as sintomatologias obsessivo-compulsivas, depressão e ansiedade nos pacientes com TOC, assim como nos delirantes. Acrescentaríamos que a PANSS foi desenvolvida para suprir a ausência de escalas com melhor padronização psicométrica. Também a dicotomia em sintomas positivos e negativos é muito questionável, até mesmo rejeitada por muitos autores ${ }^{5-6}$.

Tomando em consideração os critérios diagnósticos conhecidos, as escalas e a evolução dos pacientes, chegamos à conclusão que a observação clínica, a farmacoterapia e o acompanhamento psicoterápico dos casos foram superiores para a comprovação de nossas hipóteses iniciais: o senhor R. com o diagnóstico de transtorno delirante persistente e o senhor A. com o diagnóstico de TOC. Pondere-se, aqui, nossa opção após a prova terapêutica, a qual evidentemente não é específica. Assim apresentaremos a diferenciação entre delírio e obsessões/compulsões proposta pela psicopatologia, de forma a iluminar nossa discussão.

\section{Concepções psicopatológicas sobre delírio e pensamento obsessivo}

\section{Delírio}

Em 1913, o Tratado de psicopatologia geral de Karl Jaspers $^{7}$ conceitua delírio da forma ainda aceita pela comunidade psiquiátrica:

"De maneira vaga, chamam-se idéias delirantes todos os juízos falsos que possuem em determinado grau - não precisamente determinado - os seguintes caracteres externos: $1^{\circ}$ - A convicção extraordinária com que lhes adere, a certeza subjetiva, incomparável; $2^{\circ}-$ A impossibilidade de influenciamento da parte da experiência e de raciocínio constringentes; $3^{\circ}$ - A impossibilidade do conteúdo." (p.118)

Desde a implantação de novos códigos de doenças mentais - o americano DSM-III, em 1980, e a Classificação Internacional de Doenças (CID-10) ${ }^{8}$, de 1993, editado pela Organização Mundial de Saúde -, o delírio é definido como:

"Falsa crença baseada em inferência incorreta sobre a realidade externa, que é firmemente sustentada apesar do que os outros acreditam e apesar de seus conteúdos controversos serem óbvia prova ou evidência do contrário. Quando a falsa crença envolve um juízo de valor, é vista como delírio somente quando o juízo é tão extremo que desafia a credibilidade. Convicção delirante ocorre como uma continuidade e pode às vezes ser inferida por comportamento do indivíduo. Freqüentemente é difícil distinguir entre um delírio e uma idéia supervalorizada (neste caso o indivíduo tem irracional crença ou idéia, mas não a sustenta tão firmemente como no caso do delírio)." (p.96)

Jaspers foi uma espécie de divisor de águas para a definição de delírio. Sua concepção exprimia uma espécie de ápice para uma série de propostas, especialmente das escolas anglo-saxônica, alemã e francesa ${ }^{9}$. Em 1950, o I Congresso Mundial de Psiquiatria teve o delírio como tema principal. A partir disso, o delírio se transforma no elemento-chave para o diagnóstico de esquizofrenia. A partir da publicação do DSM-III, em 1980, o delírio como entidade nosológica (transtorno delirante) passa a ter lugar modesto nos códigos.

$\mathrm{Na}$ literatura contemporânea, termos como paranóia, parafrenia e delírios crônicos sistematizados não têm mais o destaque anterior. $\mathrm{O}$ de esquizofrenia paranóide tampouco, embora este diagnóstico esteja presente tanto no CID-10 quanto no DSM-IV. As classificações atuais privilegiam delírio como crença mórbida. Um maior interesse na evolução demencial e delírio no diagnóstico da esquizofrenia fizeram com que a paranóia não encontrasse mais lugar como patologia de referência. Foi globalmente substituída pelo conceito de transtorno delirante persistente.

Sonenreich et al. ${ }^{10}$ definem o delírio como patologia caracterizada pela perda de comunicação lógica, e é assim descrito:

"Definir o delírio pela perda da capacidade de comunicação lógica significa tratar deste conceito não como um sintoma, mas como um modo de interação com os outros. As afirmações que fazemos têm o objetivo de informar o outro, convencê-lo, eventualmente fazê-lo compartilhar conosco pensamentos e ações. Portanto, precisam ser feitas de uma maneira adequada para o outro, aceitável por ele. As noções e os termos devem significar a mesma coisa para nós."

O delirante diria, nessa proposição, coisas que não convencem de uma maneira que não convence. Não segue normas formuladas como lógicas para a transmissão de sua comunicação. Sonenreich sustenta que a característica essencial da lógica é possibilitar o entendimento $e$ a colaboração entre interlocutores. O pensamento comunicado precisa submeter-se a certas normas, garantir a identidade dos termos, a coerência. Parece-nos notável a diferença de postulados acerca do delírio e a evidente novidade da proposição de Sonenreich. Os estudos de Piaget com crianças demonstram que a forma lógica de pensar não é espontânea, e somente em torno da idade de 10 anos ela é adquirida. 
Para Jaspers, o delírio é fenômeno observável a partir da relação observador/observado, como, aliás, todos os outros sintomas. Sonenreich propõe o diagnóstico na relação: uma maneira de estar com os outros. A lógica é rompida no delírio por ser uma qualidade adquirida tardiamente, conseqüentemente mais vulnerável. Para mantê-la, são necessários esforços; portanto, permanece se os resultados adquiridos forem satisfatórios. Como o delirante não consegue alcançar seus objetivos, abandona a lógica, pois ela não serve mais como instrumento de comunicação.

\section{Pensamento obsessivo}

Do ponto de vista histórico ${ }^{11}$, obsessões e compulsões são estudadas pela medicina desde o século XIX, com seu ápice no final do século XX, quando surgiram quase que simultaneamente as propostas de Pierre Janet (1903), na França, e Sigmund Freud (1895), na Áustria.

Freud, em 1895, propôs a neurose obsessiva com mecanismos quase em oposição à histeria.

Janet, em 1903, descreve a psicastenia como patologia de gênese psicológica envolvendo idéias obsessivas, agitações forçadas: compulsões, fobias, ataques de pânico e estigmas, que seriam as doenças de personalidade, correlativas à redução da tensão psicológica, incompletude e perda da função de realidade - noção teórica que muito influenciou o conceito de autismo de Bleuler, em 1911.

Os alienistas franceses preferiram o conceito de constituição ansiosa ou emotiva de Duprè, em 1909, à psicastenia, onde manifestações obsessivas são descritas no limite das desordens delirantes crônicas (Sérieaux \& Capgras, 1909; Clérambault, 1923; Ceillier, 1924). Entre 1945 e 1980, a neurose obsessiva descrita por Freud prevaleceu nos textos e classificações franceses, enquanto a psicastenia era reduzida simplesmente a desordem de personalidade, ao lado do "caráter" anal. Desde 1980, em contraste, as classificações internacionais contemporâneas (DSM-III, DSM-IV, CID-10) e os estudos de comorbidade dos transtornos obsessivos com outros distúrbios de ansiedade, transtornos depressivos, ciclotimia e personalidade obsessivo-compulsiva parecem validar os pontos de vista de Janet ${ }^{12}$.

\section{Concepção atual da CID-10 F42- F42: transtorno obsessivo- compulsivo}

Transtorno caracterizado, essencialmente, por idéias obsessivas ou por comportamentos compulsivos recorrentes. As idéias obsessivas são pensamentos, representações ou impulsos que se intrometem na consciência do sujeito de modo repetitivo e estereotipado. Em regra geral, elas perturbam muito o sujeito, o qual tenta freqüentemente resistir-lhes, mas sem sucesso. O sujeito reconhece, entretanto, que se tratam de seus próprios pensamentos, mas estranhos à sua vontade e, em geral, desprazerosos. Os comportamentos e os rituais compulsivos são atividades estereotipadas repetitivas. O sujeito não tira prazer direto algum da realização desses atos, os quais, por outro lado, não levam à realização de tarefas úteis por si mesmas. O comportamento compulsivo tem por finalidade prevenir algum evento objetivamente improvável que o sujeito teme possa ocorrer, implicando dano a si mesmo ou sendo causado por ele. O sujeito reconhece habitualmente o absurdo e a inutilidade de seu comportamento e faz esforços repetidos para resistirlhes. O transtorno se acompanha quase sempre de ansiedade. Esta ansiedade se agrava quando o sujeito tenta resistir à sua atividade compulsiva.

Nas definições dos manuais de psiquiatria, assim como no DSM-IV e CID-10, não há nenhuma contribuição psicopatológica para a compreensão e mesmo distinção entre pensamentos obsessivos no seu limite e delírios, ainda que a clínica nos obrigue a refletir sobre a questão.

Sonenreich et al., apoiando-se em Pierre Janet, entendem as obsessões e compulsões como um espectro mais amplo, que também inclui a fobia. Sonenreich propõe o estudo deste capítulo em termos psicológicos, "como resultante de conflitos, investimentos insuficientes ou inadequados para responder às situações" (p. 123).

\section{Discussão}

Os dois casos descritos acima podem apontar para dificuldades encontradas na clínica entre a psicopatologia do delírio e do pensamento obsessivo. Os critérios de diagnóstico propostos pelo DSM-IV e CID-10 nos permitem formular tanto a hipótese de quadro delirante quanto de obsessivo-compulsivo em ambos os casos. Pensamos que o apuro psicopatológico nos obriga a ir além dos conceitos de comorbidade, que podem facilitar o diagnóstico por sintomas, mas não inspiram reflexões mais profundas.

Um paciente, o senhor R., acreditando-se iluminado e escolhido por Deus, portanto delirante, executa atos repetitivos - de caráter evidentemente simbólico compulsivamente, na certeza de assim executar melhor o que o Senhor lhe ordena e seguro que será castigado se não o fizer.

Seriam, então, os critérios de insight no delírio ${ }^{7}$, ou seja, de que a idéia não lhe é própria, suficientes 
para distingui-lo do pensamento obsessivo, onde o paciente sabe que a idéia é autóctone, isto é, lhe pertence?

Muitas publicações têm ressaltado a dificuldade na diferenciação entre as sintomatologias do TOC e do delírio e constataram que alguns casos de TOC se confundem com transtornos delirantes ${ }^{13}$.

Portela Nunes ${ }^{14}$, no seu trabalho de livre-docência e posterior livro de 1976, afirma a diferença entre delírio e obsessão a partir de categorias mais amplas como psicose e neurose. Para o autor, esses conceitos confundir-se-iam se analisados fora das grandes síndromes de referência.

Para Palomo Nicolau et al. ${ }^{15}$, a transição entre o TOC e o delírio varia como espectro em que pesa a capacidade de o paciente fazer insights.

Fear \& Healy ${ }^{16}$ afirmam que, surpreendentemente, nos pacientes obsessivos e delirantes avaliados, estes obsessivos respondem de maneira menos "normal" que os delirantes, apoiando de forma tímida a idéia de que algo comum às duas patologias serviria para melhor compreendê-las.

Phillips et al. ${ }^{17}$ acreditam que, diferentemente do DSM-III-R, não faz sentido excluir ou encapsular a psicose em capítulos separados dos outros quadros. Concluem que as alterações de imagem corporal em transtornos dismórficos e alimentares podem ser creditados a ambos, delírios e obsessões. A variabilidade de insight aconteceria dentro de um espectro. Afirmam ainda que, pelo DSM-IV - na base de evidências empíricas -, os limites entre delirante e não-delirante seriam menos claros ainda que na revisão anterior.

Kitis \& Akdede $^{18}$, em artigo de 2006, afirmam que disfunções cognitivas em pacientes com TOC, em comparação com pacientes esquizofrênicos, apresentam a mesma relação com idéias supervalorizadas. Consideram, inclusive, que as observações clínicas mostram sobreposição entre esquizofrenia e transtorno obsessivo no campo relacionado às alterações do pensamento, que envolveria obsessões, idéias sobrevalorizadas e delírios. Não há uma caracterização psicopatológica precisa diferenciando essas alterações do pensamento. A conclusão seria que, no TOC, podem ser relacionadas disfunções cognitivas semelhantes às encontradas nos delirantes.

Autores que estudaram as diferenças entre os transtornos delirantes e os obsessivo-compulsivos constataram as dificuldades e as confusões possíveis entre estas categorias diagnósticas ${ }^{19}$.

\section{Uma proposta para a diferenciação entre obsessão, compulsão e delírio}

Nos estudos atuais de psicopatologia, não encontramos referência clara que possa facilitar a distinção entre essas duas categorias, o que implicaria em conduta terapêutica diferenciada.

Segundo Jaspers, um delirante nunca poderia admitir-se como doente. O critério de insight (Jaspers), ou seja, o paciente ter ciência de sua perturbação perceber que o pensamento é dele - aponta-nos para a psicastenia (TOC) na atualização proposta por Sonenreich.

Ainda segundo esse autor, o critério da perda de comunicação lógica nos dirige para o delírio. Estar com os outros é uma construção baseada em experiências de sucesso e de fracasso; o discurso, com a maturidade psíquica, aprimora-se, amplia-se em possibilidades e capacidade de abstração e reconhecimento. No delirante, isso se perde de maneira absoluta.

O critério descritivo, de soma de sintomas, não elimina a discussão. Não nos ajuda também a separação em categorias diagnósticas proposta pelos manuais e códigos que colocam o delírio entre os transtornos cognitivos e o TOC como transtorno de ansiedade. Estudos recentes, citados acima, assinalam as dificuldades em caracterizar as diferenças na cognição do delirante e do paciente com TOC. Conforme apontamos anteriormente, os critérios do DSM-IV, CID10 e algumas das escalas mais utilizadas para a pesquisa de delírio ou da obsessão/compulsão, que têm como referência o sintoma, nos proporcionaram sobreposição de idéias, confusão diagnóstica. $\mathrm{O}$ mesmo paciente poderia ser considerado delirante ou obsessivocompulsivo.

A escala Yale-Brown - a mais usada - nos parece imprecisa, pois confunde obsessão e fobia. $\mathrm{Na}$ escala de avaliação dos sintomas obsessivos, o medo ocupa o primeiro lugar: medo de se ferir, de ferir outros, de dizer obscenidades, de roubar, de executar impulsos, o que nos parece a principal questão do quadro. Mesmo sem a intenção de dirigir para um diagnóstico, não há separação precisa entre esses sintomas.

Optamos, assim, por uma reflexão sobre a maneira de o paciente estar conosco. O que nomeamos ruptura da comunicação lógica seria um modo de viver que abole o outro e a lógica básica da comunicação; não há argumentação ou vontade de convencer. O paciente R. (caso 1) isola-se de forma autista, ou, melhor ainda, solipsista, só conseguindo falar dos temas delirantes, sem nenhuma preocupação com qualquer prova de realidade e compartilhamento. A ruptura com o outro, a falha em considerar uma segunda possibilidade, o discurso cheio de jargões, lugares-comuns e a incapacidade de reconhecer em si o fracasso tornam as diferenças entre a psicopatologia obsessivo-compulsiva e o delírio mais claras.

Não duvidamos que haja angústia, mas esta se restringe ao tema do delírio sem questionamento algum. Já o segundo caso nos lembra de $\mathrm{Ey}^{20}$, que descrevia os 
obsessivos como tendo "a angústia como lei de sua existência". Incapaz de livrar-se das idéias e compulsões, que entendemos associadas às fobias, exaure sua existência numa luta contínua e inesgotável, resultando em inexorável enfraquecimento e esgotamento, portanto psicastenia. Esta poderia inclusive ser mais uma diferença: o fato de o delirante preservar a energia psíquica que nos obsessivos esvai-se com facilidade. Se for possível pensar numa fórmula para a existência do obsessivo, esta seria: não consigo controlar minhas idéias e minhas condutas, resultando disso uma insuportável angústia. $\mathrm{O}$ apuro psicopatológico nos obriga a ir além do conceito de comorbidade, que pode facilitar o diagnóstico por sintomas, mas não inspira reflexões mais profundas.

\section{Conclusões}

Sendo este um trabalho de debate em psicopatologia, nossos resultados visaram ao esclarecimento do estado da arte dos conceitos de delírio e pensamento obsessivo. No delírio, predominaria a impossibilidade de reconhecimento do fracasso com a perda da comunicação lógica. A característica principal do obsessivo seria a impossibilidade de controle das idéias e condutas, resultando em angústia. A apreciação de sua aplicação no diagnóstico psiquiátrico poderá iluminar as indagações mais comuns relativas ao diagnóstico diferencial, apontando para novas propostas e, conseqüentemente, condutas mais efetivas.

\section{Agradecimentos}

Agradecemos ao Prof. Dr. Carol Sonenreich, diretor do Serviço de Psiquiatria do Hospital do Servidor Público Estadual de São Paulo, que nos agraciou com sua co-orientação e sugestões.

\section{Referências}

1. DSM-IV. Manual Diagnóstico e Estatístico de Transtornos Mentais. $4^{\mathrm{a}}$ ed. Porto Alegre: Artmed; 1995.

2. Chaves AC, Shirakawa I. Escala das Síndromes Negativa e Positiva e seu uso no Brasil. In: Gorenstein C, Andrade LHSG, Zuardi AW. Escalas de avaliação clínica em psiquiatria e psicofarmacologia. São Paulo: Lemos; 2000. p. 219-25.

3. Asbahr FR. Escalas de avaliação do transtorno obsessivocompulsivo na infância e adolescência. In: Gorenstein C, Andrade LHSG, Zuardi AW. Escalas de avaliação clínica em psiquiatria e psicofarmacologia. São Paulo: Lemos; 2000. p. 167-80.

4. Araújo LA. Escalas de avaliação de transtorno obsessivocompulsivo em adultos. In: Gorenstein C, Andrade LHSG, Zuardi AW. Escalas de avaliação clínica em psiquiatria e psicofarmacologia. São Paulo: Lemos; 2000. p. 166.

5. Elkis H. Contribuição para o estudo da estrutura psicopatológica multifatorial da esquizofrenia (tese). Rev Psiq Clin. 1997:23/24(4/ $1-3): 34-5$

6. Lezenweger MF, Dworkin. The dimensions of schizophrenia phenomenology: not one or two, at least three, perhaps four. Brit J Psychiatry. 1996;168:432-40.

7. Jaspers K. Psicopatologia geral. Rio de Janeiro: Atheneu; 1979.

8. Organização Mundial da Saúde. Classificação de transtornos mentais e de comportamento da CID-10: descrições clínicas e diretrizes diagnósticas. Porto Alegre: Artmed. 1993.

9. Berrios GE. The history of mental symptoms. Cambridge: Cambridge University; 1996.

10. Sonenreich C, Estevão G, Silva Filho LMA. Psiquiatria: propostas, notas, comentários. São Paulo: Lemos; 1999.

11. Shorter E. A historical dictionary of psychiatry. New York: Oxford University; 2005.

12. Haustgen T. À propos du centenarie de la psychasthénie. Les troubles obsessionnels-compulsifs dans la psychiatrie française: revue historique. Annales Medico Psychologiques. 2004;162:427-40.

13. Aardema F, O'Connor KP, Emmelkamp PM, Marchand A, Todorov C. Behav inferencial confusion in obsessive-compulsive disorder: the inferencial confusion questionnaire. Res Ther. 2005;43(3):293-308.

14. Portella Nunes E. Obsessão e delírio: neurose e psicose. Rio de Janeiro: Imago; 1976.

15. Palomo Nicolau AL, Alcoverro Fortuny O, Hurtado Ruiz G, Guerrero Pedraza A. In thoughts disorders in obsessive-compulsive disorder. Actas Esp Psiquiatr. 2003;31(2):100-2.

16. Probabilistic reasoning in obsessive-compulsive and delusional disorders Psychol Med. 1997;27(1):199-208.

17. Phillips KA, Kim JM, Hudson JI. Body image disturbance in body dysmorphic disorder and eating disorders. Obsessions or delusions? Psychiatr Clin North Am. 1995;18(2):317-34.

18. Kitis A, Akdede BB, Alptekin K, Akvardar Y, Arkar H, Erol A, et al. Cognitive dysfunctions in patients with obsessive-compulsive disorder compared to the patients with schizophrenia patients: relation to overvalued ideas. Prog Neuropsychopharmacol Biol Psychiatry. 2007;31(1):254-61.

19. Torres AR. Relações entre sintomas fóbicos e obsessivocompulsivos. Temas vol. 4. $\mathrm{n}^{\circ} 48$. 1994. p. 159-70.

20. Ey H, Bernard P, Brisset C. Manual de psiquiatria. Rio de Janeiro: Masson; 1981. 